\title{
A Study of Prevalence of Obesity among Female Students in Sohag University
}

\author{
Farida S. Abdou, Ahmed F. Hamed, Eman R. Mohammed and Nesreen A. \\ Mohammed \\ Department of Family Medicine, Faculty of Medicine, Sohag University
}

\section{Abstract}

Introduction: Obesity is a medical case in which extra body fat has stored to the extent that it may have a harmful effect on health. People are generally measured obese when their body mass index (BMI), ameasurement obtained by dividing aperson's weight by the square of the person's height, is over $30 \mathrm{~kg} / \mathrm{m} 2$, with the range $25-30 \mathrm{~kg} / \mathrm{m} 2$ defined as overweight. Some East Asian countries use lower values.

Aim of the work: Find out the prevalence of overweight and obesity among female students in Sohag University, and identify important risk factors.

Patients and Methods: Cross sectional study, included a sample of female students aged 1725 in the selected faculties in Sohag University, the study was carried out in Faculty of Medicine, Faculty of Nursery and Faculty of Education in Sohag University, the questionnaire was divided into five parts, the demography, dietary habits, physical activity, perceptions of body weight and beliefs of obesity and the record of self-reported and actual anthropometric body measurements.

Results: Overweight and obesity were prevalent among the our study subjects as the prevelance was $38.5 \%$, lack of physical activity, soft drink consumpton and marital status were significantly associated with obesity, our students preferred dairy products and fatty foods over vegetables and fruits. In addition, their "lack of time" was the most frequently mentioned barrier to eating a healthy diet and engaging in regular exercise. Life style modification is important to improve healthy habits earlier in life.

Conclusion: Overweight and obesity were prevalent among the our study subjects as the prevelance was $38.5 \%$.

Key words: Obesity, female, sohag university.

\section{Introduction}

Obesity is a medical case in which extra body fat has stored to the extent that it may have a harmful effect on health. People are generally considered obese when their body mass index (BMI), ameasurement obtained by dividing aperson's weight by the square of the person's height, is over $30 \mathrm{~kg} / \mathrm{m} 2$, with the range $25-30 \mathrm{~kg} / \mathrm{m} 2$ defined as overweight. Some East Asian countries use lower values ${ }^{(1)}$.

Obesity is most commonly caused by acombination of extreme food intake, physical inactivity, and genetic predisposition. A little cases are caused primarily by genes, endocrine diseases, medication, or mental illness. Suggestion to support the view that obese people eat minute yet gain weight due to a slow metabolism is not generally maintained. On usual, obese people have better energy expenditure than their thin counterparts due to the energy required to maintain an increased body mass. Obesity increases the likelihood of various diseases, particularly heart disease, type 2 diabetes, obstructive sleep apnea, certain types of cancer and osteoarthritis ${ }^{(2)}$.

The percentage of adolescents who are overweight or obese is quickly increasing worldwide. Adolescence is a susceptible period for the development of obesity and also appears to be a serious period for creating risk factors for some chronic diseases in adulthood. Existing statistics indicate that an alarming percentage of people in most arab countries hurt from obesity. Studies have exposed that the incidence of overweight and obesity among adolescents in arab countries ranges from $18 \%$ to $44 \%$. Overall, overweight has been found to be more predominant than obesity in both males and females. However, 
the incidence of obesity by gender at the adolescent period (10-18 years) does not indicate the same trend. In countries such as Bahrain, Egypt, Tunisia, Kuwait, and Qatar, the incidence of overweight is higher among females than males. In some countries such as Lebanon and the United Arab Emirates (UAE), the incidence of overweight and obesity is higher in boys than girls ${ }^{(3)}$.

\section{Aim of the work}

Aim of this survey was to find out the of overweight and obesity among fem prevalence ale adolescents in Sohag University, and identify important risk factors.

\section{Participants and methods}

Design: Cross sectional study.

The study was carried out in Faculty of Medicine, Faculty of Nursery and Faculty of Education in Sohag University.

\section{The sample size:}

The study included 600 students.

\section{Sampling technique:}

Students selected using the multistage stratified random sampling technique as follow:

Faculties in the university were divided into medical and non medical faculties.

Therefore, Faculties were chosen randomly from each stratum; Faculty of Medicine and Faculty of Nursery were chosen from the medical faculties and Faculty of Education and were chosen from non medical faculties.

Stratification of the educational grades in each faculty was done and from each grade, students selected by clustered random sampling technique.

\section{- Data collection}

Data was collected through personal interviews with the females from the predetermined places using a questionnaire after explaining nature and aim of study.

A questionnaire was filled through interviewing the participating students with measuring weight, height and body mass index where weight and height were measured and body mass index to determine overweight and obesity using WHO international standards.

\section{Description of the questionnaire}

The questionnaire was divided into five parts. The demography, dietary habits, physical activity, perceptions of body weight and beliefs of obesity and the record of self-reported and actual anthropometric body measurements.

Part One: The demography section has 10 questions and it served as an introduction to the survey. Questions 1-3 were openended questions while questions 4-10 were Likert scale questions.

Part Two: In the dietary habit section, eight questions on frequency of certain foods eaten and the choice of foods eaten were asked.

Part Three: There were 12 questions on the frequency of physical activity and how active the participants are. Examples of active exercises were given in the questionnaire. If they were not physically active, the respondents were required to give the reasons why they did not engage in physical activities.

Part Four: Six questions on the perceptions of obesity and beliefs about overweight were asked in this part of the questionnaire. Participants were asked to assess their weight status. This was achieved by giving them choices of weight (underweight, normal, overweight and obese) from which they had to choose whichever was most applicable to them. Respondents were also asked if they would like to lose weight and how they believed overweight could best be treated. Part Five: The last part of the questionnaire consisted of the record of the anthropometric measurements/data. Participants wrote down their weight in kilograms, height and waist circumference in centimetres. Afterwards, the weight, height and waist circumference of the respondents were me C) 3rd phase Analysis of data and presentation:

\section{Statistical analysis:}

- Computer data entry and data cleaning done along the period spent on data collection

- Data subjected to statistical analysis and tabulation using SPSS program version 16, the results presented to fulfill the objectives of the study.

\section{Ethical consideration:}

- Approval of Ethical Committee of Sohag Faculty of Medicine secured. 
- A written informed consent obtained from the responsible administrative authorities after explaining the objectives and the steps of the study to the participants, before taking any information.
- Ethical consideration was observed in each step of the study including written consent of patients.

- The questionnaire used in data collection was anonymous and confidentiality was assumed.

\section{Results}

The total number of participants in this survey was 600 female, included 369 $(61.5 \%)$ participants with normal BMI $(\mathrm{BMI}=20: 25)$ and $231(38.5 \%)$ participants overweight and obese (BMI >25) as shown in figure 1. Mean age was similar in two groups of participants. No association between BMI status and fathers ${ }^{e e}$ education level and motherse education level. Regarding marital status there were significant difference between both groups ( $p$ value $<0.001$ ). Weight, height, waist circumference and BMI of participants is summarized in table 1. The mean value of weight was 56.6 $\mathrm{kg}$ in normal group while the mean value of weight was $70.9 \mathrm{~kg}$ in overweight or obese group. In addition, the mean value of height was $158 \mathrm{~cm}$ in normal group while the mean value of height was $159 \mathrm{~cm}$ in overweight or obese group. The average waist circumference was 72.3 in normal group while it was 80.9 in obese group. Mean value of BMI was 22.5 in normal group and 27.9 in overweight or obese group. All these difference was high significant ( $p$ value $<0.001$ ), but it was non-significant for length. A high percentage of the respondents in obese group have a family history of obesity with high significant difference $(\mathrm{p}<0.001)$ and the majority were not taking any medication in both groups. There was no relation between BMI status and participants medication intake. Dietary behaviors and food consumption patterns of our participants is summarized in table 2. Breakfast is a very important meal of the day due to the fact that it gives the energy needed for going about the day's activities. Information on the breakfast habits and its influence on the BMI status of the participants are given in Table 4. Our findings show a significant relationship between BMI status and breakfast intake $(\mathrm{p}=0.008)$ and reason for no breakfast intake $(\mathrm{p}<0.001)$.

Over four percent $(4.6 \%)$ of the participants in normal group never had breakfast and $5.2 \%$ of obese group never had breakfast. High percentage of overweight or obese $(36.8 \%)$ had breakfast intake one-nine times while $25.5 \%$ of normal group had breakfast intake one-nine times. Over thirty-five percent $(35.9 \%)$ of overweight or obese participants had breakfast intake for ten-nineteen times while $37.4 \%$ of normal group had breakfast intake for ten-nineteen times. The main reason for skipping breakfast among overweight or obese participants was lack of time, also it was the main cause in normal participants. Fruit seem to be consumed at least once per day by most participants in both groups. There was no association between the BMI status of participants and fruit consumption.

Figures 2 and 3 show fast foods consumption, vegetables and soft drinks consumption. Vegetables seem to be consumed at least once per day by most participants in both groups. There was no association between the BMI status of participants and vegetables consumption.

The relation between fast foods consumption and respondentse BMI status was high significant $(\mathrm{p}<0.001)$. Also, there was high significant association found between BMI status and soft drinks ( $\mathrm{p}<0.001)$. The highest percentage $(39.4 \%)$ of overweight or obese participants consumed soft drink once daily while the lowest percentage $(1.7 \%)$ was found for 4 times consumption. However, $33.3 \%$ who were not overweight or obese consumed soft drinks once daily. High percentage of normal 
participants $(23.8 \%)$ not drinks any soft drinks while only $13.4 \%$ of overweight or obese participants not drink any soft drinks. Highest percentage of normal participants $(38.8 \%)$ not takes fast foods last week while highest percentage of overweight or obese participants $(38.5 \%)$ had taken fast foods last week once.

Dairy products and fatty food consumption is summarized in table 3. Dairy products and fatty food consumption was significantly associated with the BMI status ( $\mathrm{p}=0.01$, 0.002 respectively). $12.7 \%$ of normal participants had no dairy products, $48.8 \%$ consumed dairy products once daily, $18.7 \%$ had dairy products twice daily while $3.8 \%$ had dairy products 3 times daily, on the other hand, $8.2 \%$ of overweight or obese participants had no dairy products, $47.6 \%$ consumed dairy products once daily, $27.3 \%$ had dairy products twice daily while $6.5 \%$ had dairy products 3 times daily. Also regarding fatty food, we found that highest percentage of participants in overweight or obese group consumed fatty food twice but highest percentage of participants in normal group consumed fatty food once. Dairy products and fatty food consumption was significantly associated with the BMI status $(\mathrm{p}=0.01,0.002$ respectively). $12.7 \%$ of normal participants had no dairy products, $48.8 \%$ consumed dairy products once daily, $18.7 \%$ had dairy products twice daily while $3.8 \%$ had dairy products 3 times daily, on the other hand, $8.2 \%$ of overweight or obese participants had no dairy products, $47.6 \%$ consumed dairy products once daily, $27.3 \%$ had dairy products twice daily while $6.5 \%$ had dairy products 3 times daily. Also regarding fatty food, we found that highest percentage of participants in overweight or obese group consumed fatty food twice but highest percentage of participants in normal group consumed fatty food once.

Figure (4) show details of participants' heavy exercise. The relation between BMI status and heavy exercise $(\mathrm{p}=0.04)$ and the duration of exercise $(\mathrm{p}=0.01)$ were significant. However, BMI status was non significantly associated with cause if no activity. Over eighty eight $88.3 \%$ of the overweight or obese participants that did no heavy activity, a nearly similar percentage $(80.2 \%)$ from normal participants. The reason most often given for not participating in heavy activity was lack of time in both groups. the relation between BMI status and light activity and the cause if no activity were non significant. However, BMI status was significantly associated with duration of exercise $(\mathrm{p}=0.01)$.

Over sixty seven $67.1 \%$ of the overweight or obese participants that did no light activity, while $59.6 \%$ from normal participants did no light activity. The reason most often given for not participating in light activity was lack of time in both groups. BMI was significant related to walking 10 minutes $(\mathrm{p}=0.02)$ and walking duration lately ( $\mathrm{p}=0.003$ ) but it non-significant related to cause if no walking.

Most of the participants in both groups (over twenty-eight percent $28.1 \%$ were overweight or obese whereas $22 \%$ were not overweight) walked for at least ten minutes during the last seven days before the survey for two days. Only few participants ( 2 participants from normal and 1 participant from overweight or obese) reported that they did not walk. Of those who reported walking four or more days per week, $>38 \%$ were overweight or obese compared with $>40 \%$ who were not. The majority of the participants in both groups did not report lack of time as a reason for not walking because most participants reported walking for at least ten minutes in the past seven day.

There was no statistically significant relationship between participants ${ }^{\text {ee }}$ BMI status and time spent sitting idle, time spent on the computer and time spent watching TV. Regarding idle sitting time, $38.1 \%$ of overweight and obese participants sat idle for 
four or more hours per day. More than $44 \%$ of overweight or obese participants reported watching TV for 2 or more hours per day.

over eighty five percent $85.4 \%$ of normal participants did not want to lose weight while $5.4 \%$ were not sure, however $90.9 \%$ of overweight or obese participants want to lose weight while $4.8 \%$ were not sure, there was high significant relation between BMI and beliefs of participants about weight loss ( $p<0.001)$.

Regarding cause of weight loss, there was also high significant relation between BMI and beliefs of participants about cause of weight loss ( $p<0.001)$, the table shows that $38.1 \%$ of overweight or obese participants and 3.3\% of those who were not overweight wanted to lose weight for appearance. In terms of better health, 28.6\% who were overweight or obese as well as $4.1 \%$ who were not overweight wanted to lose weight for better health. For good life, $4.8 \%$ of overweight or obese participants and $1.1 \%$ who were not overweight wanted to lose weight for good life. Over one percent $(1.3 \%)$ of overweight or obese and none of those who were not overweight wanted to lose weight for fitness and do sport.

Over nineteen percent (19.9\%) who were overweight or obese and $2.2 \%$ who were not overweight wanted to lose weight because of problems with clothes sizes. Highest percentage of participants in both groups believed that obesity heredity was little important. Also highest percentage of participants in both groups believed that obesity reduced by diet, with non significant difference.

$45.8 \%$ of normal and $53.7 \%$ of overweight or obese participants believed that obesity may best be treated by the individual's effort to change the diet and exercise regime. In terms of the best way to treat obesity, $45 \%$ of normal and $38.5 \%$ of overweight or obese believed in the dietitian as the best treatment method for combating obesity. The least common treatment option was surgery $0 \%$ of overweight or obese and $0.3 \%$ of normal participants.

Regression analysis is used to detect the factors which can be used to "predict" certain outcome and summarized in tables 4, 5, 6. All possible variables were introduced into a univariate binary logistic regression analysis. The factors which showed non significant effect were excluded from the subsequent analysis.

Univariate analysis showed marital status $(\mathrm{p}=<0.001)$, soft drinks $(\mathrm{p}=0.05)$, exercise ( $\mathrm{p}=0.01)$, watching TV $(\mathrm{p}=0.05)$ were significantly associated with obesity, whereas age, breakfast, eating fruits and vegetables, and walking 10 minutes were not. Factors which showed significant effect by univariate regression were evaluated for possible association and interaction, by multivariate regression analysis (Table 13) showed that marital state $(\mathrm{p}=<0.001, \mathrm{OR}=3.383, \mathrm{CI}=1.730-6.614)$, exercise $(\mathrm{p}=0.017, \mathrm{OR}=1.1771$, $\mathrm{CI}=1.106-2.834)$, and watching TV $(\mathrm{p}=0.031, \mathrm{OR}=0.503, \mathrm{CI}=0.269-0.941)$ were independent factors that predict overweight or obese participants from normal BMI participants.

\section{Discussion}

The total number of participants in this survey was 600 female, included $369(61.5 \%)$ participants with normal BMI (BMI =20:25) and 231 (38.5\%) participants with BMI >25 were overweight or obese. Our results regarding prevalence of obesity were higher than the results of Sengupta et al. ${ }^{(4)}$ in India where the prevalence of overweight was (11.3\%) and that of obesity was $(8.1 \%)$. The prevalence of obesity in the United States continues to be high, exceeding $30 \%$ in most sex and age groups. Comparisons between Canada and the United States show that obesity prevalence was higher in the United States in1999-2002 than in Canada in 2004, with the difference 
largely due to higher obesity prevalence among women ${ }^{(5)}$.

Comparisons of obesity prevalence between Canada and the United States that are limited to white adults show no significant differences for men ${ }^{(5)}$. A review of prevalence estimates in European countries found that the prevalence of obesity based on measured weights and heights varies widely from country to country, with higher prevalence in Central, Eastern, and Southern Europe ${ }^{(6)}$. In most cases, the prevalence of obesity appeared lower in European countries than in the United States. However, estimates from other countries are not precisely comparable with US estimates because of differences in study methods, years of measurement and the age ranges, and methods of age adjustment or age categorization $^{(6)}$.

In the current study, the mean value of weight in normal group was $56.6 \mathrm{~kg}$ while the mean value of weight was $70.9 \mathrm{~kg}$ in overweight or obese group. In addition, the mean value of height was $158 \mathrm{~cm}$ in normal group while the mean value of height was $159 \mathrm{~cm}$ in overweight or obese group. The average waist circumference was 72.3 in normal group while it was 80.9 in obese group. Mean value of BMI was 22.5 in normal group and 27.9 in overweight or obese group. All these differences ware highly significant $(\mathrm{p}$ value $<0.001$ ), but it wasn't significant for length ( $p$ value $=0.08$ ).

Mean age of participants in this survey was similar in two groups, highest percentage of participants in both groups was from the faculty of education. The smallest percentage of participants was from the Faculties of medicine and nursing. Regarding marital status there were significant difference between both groups (pvalue $<0.001)$. No association between BMI status and fathers 'education level and mothers' education level, but the study of Berghöfer et al. ${ }^{(6)}$, showed significant statistical association between overweight and obesity and parents' education ( $\mathrm{p}$-value <0.001). These findings were also supported by Adesina et al. (7) who found that the percentage of overweight subjects whose mothers were highly educated was higher $(9.7 \%)$.

We found that a high percentage of the respondents in obese group had a family history of obesity with highly significant difference ( $p$-value $<0.001)$ and the majority were not taking any medication in both groups. There was no relation between BMI status and participants medication intake.

Breakfast is a very important meal of the day due to the fact that it gives the energy needed for going about the day's activities. Our findings show a significant relationship between BMI status and breakfast intake (pvalue $=0.008$ ) and the reason for no breakfast intake $(\mathrm{p}<0.001)$. More than four percent $(4.6 \%)$ of our participants in normal group never had breakfast and $5.2 \%$ of the obese group never had breakfast. High percentage of the overweight or obese $(36.8 \%)$ had breakfast intake one-nine times while $25.5 \%$ of the normal group had breakfast intake 1-9 times. Over thirtyfive percent $(35.9 \%)$ of overweight or obese participants had breakfast intake for 10-19 times while $37.4 \%$ of normal group had breakfast intake for 10-19 times.

The main reason for skipping breakfast among overweight or obese participants was lack of time, also it was the main cause in normal participants. Another research reported that $61.4 \%$ of Lebanese university students had regular meals daily ${ }^{(8)}$. As reported by various studies, skipping breakfast is one of the proven factors to induce obesity. It resulted in a lack of a feeling of satiety and lead to 
increased total energy intake and obesity ${ }^{(9)}$.

Fruit seem to be consumed at least once per day by most participants in both groups in our survey. There was no association between the BMI status of participants and fruit consumption. Vegetables seem to be consumed at least once per day by most participants in both groups. There was no association between the BMI status of participants and vegetables consumption.

Similar findings were reported by Yahia et al. ${ }^{(8)}$ in which the majority of participants consumed vegetables and fruits three or more times a week $(81.8 \%)$, almost half of them $(51.5 \%)$ consumed fruits less than three times a week; the rest $(48.5 \%)$ took it three times or more. Most of them had a balanced variety of foods $(60.6 \%)$ while $18.9 \%$ preferred meat and $5.3 \%$ preferred vegetables ${ }^{(8)}$.

We demonstrated that the relation between fast foods consumption and respondents' BMI status was highly significant $(\mathrm{p}<0.001)$, More than one third of the normal participants (38.8\%) didn't take fast foods in the last week while more than one third of the overweight or obese participants $(38.5 \%)$ had taken fast foods once last week. Comparable results were found in the Malaysian survey in which only $21.2 \%$ of the respondents consumed fast-food ${ }^{(10)}$. In contrast, Moy et al. ${ }^{(11)}$ reported that $60-70 \%$ of the students were fond of fast food.

Furthermore, the current study reported a highly significant association between BMI status and soft drinks ( $\mathrm{p}$ value $<0.001)$. More than one third $(39.4 \%)$ of overweight or obese participants consumed soft drink once daily while only $1.7 \%$ reported 4 times consumption. However, $33.3 \%$ participants with normal weight consumed soft drinks once daily. While $23.8 \%$ of normal participants didn't drink any soft drinks while only $13.4 \%$ of overweight or obese participants didn't drink any soft drinks. Similarly results were conducted in UiTMPuncakAlam showed that $11.7 \%$ of the students consumed soft drink at least three or four times per week. High intake of soft drink led to high risk of chronic disease such as diabetes and hypertension. Moreover, the prevalence of overweight and obesity was increasing due to high consumption of sugar-sweetened beverages ${ }^{(12)}$.

In our study, the dairy products and fatty food consumption was significantly associated with the BMI status $\quad(p$-value $=0.01, \quad 0.002$ respectively). $12.7 \%$ of normal participants didn't consume dairy products, $48.8 \%$ consumed dairy products once daily, $18.7 \%$ consumed dairy products twice daily while $3.8 \%$ consumed dairy products 3 times daily, On the other hand, $8.2 \%$ of overweight or obese participants reported no dairy products consumption, $47.6 \%$ consumed dairy products once daily, $27.3 \%$ consumed dairy products twice daily while $6.5 \%$ consumed dairy products 3 times daily. In addition, regarding fatty food, we found that the participants in the overweight or obese group consumed fatty food twice but the participants in normal group consumed fatty food once.

Regarding activity, we found that the relation between BMI status and heavy exercise ( $p$-value $=0.04)$ and the duration of exercise ( $\mathrm{p}$-value $=0.01$ ) were significant. However, BMI status was non significantly associated with cause if no activity.

Over eighty eight $88.3 \%$ of our overweight or obese participants did no heavy activity, a nearly similar percentage $(80.2 \%)$ from normal participants. The reason most often given for not participating in heavy 
activity was lack of time in both groups. The relation between BMI status and light activity and the cause of no activity were non significant. However, BMI status was significantly associated with the duration of exercise (p-value $=0.01)$. Over sixty seven $67.1 \%$ of the overweight or obese participants didn't do light activities, while $59.6 \%$ of the normal participants did no light activity. The reason most often given for not participating in light activity was lack of time in both groups. BMI was significant related to walking for 10 minutes ( $\mathrm{p}$-value $=0.02$ ) and walking duration ( $\mathrm{p}$-value $=0.003$ ) but it wasn't significant related to the cause of not walking.

Most of our participants in both groups (over twenty-eight percent $28.1 \%$ were overweight or obese whereas $22 \%$ were not overweight) walked for at least ten minutes during the last seven days before the survey for two days. Only few participants (2 participants from the normal group and 1 participant from the overweight or obese group) reported that they did not walk. Of those who reported walking four or more days per week, $>38 \%$ were overweight or obese compared with $>40 \%$ who were not. The majority of the participants in both groups did not report lack of time as a reason for not walking because most participants reported walking for at least ten minutes in the past seven day.

Regarding sitting time, we found that there was no statistically significant relationship between participants' BMI status and time spent sitting, time spent on the computer and time spent watching TV. Regarding idle sitting time, $38.1 \%$ of the overweight and obese participants sat idle for four or more hours per day. More than $44 \%$ of the overweight or obese participants reported watching TV for 2 or more hours per day. In another study, Pinto and Marcus. ${ }^{(13)}$ reported that despite awareness of the benefits of exercise, only $35 \%$ of the students had a regular schedule of physical activity, while there was slightly better adherence to exercise by males $(40 \%)$ than females $(32 \%)$. Another study showed that most students had light physical activity levels, particularly women ${ }^{(14)}$. Regarding beliefs about obesity, we found that over eighty five percent $(85.4 \%)$ of the normal participants did not want to lose weight while $5.4 \%$ were not sure, however $90.9 \%$ of the overweight or obese participants want to lose weight while $4.8 \%$ were not sure, there was high significant relation between BMI and beliefs of participants about weight loss ( $\mathrm{p}$-value $<0.001$ ).

Regarding the purpose of weight loss in our study, there was also a highly significant relation between BMI and beliefs of participants about cause of weight loss (p-value $<0.001$ ), $38.1 \%$ of the overweight or obese participants and $3.3 \%$ of those who were not overweight wanted to lose weight for appearance. In terms of better health, $28.6 \%$ of those who were overweight or obese as well as $4.1 \%$ of those who were not overweight wanted to lose weight for better health. For good life, near 5 percent $(4.8 \%)$ of the overweight or obese participants and $1.1 \%$ of those who were not overweight wanted to lose weight for good life. Over one percent $(1.3 \%)$ of the overweight or obese students and none of those who were not overweight wanted to lose weight for fitness and for doing sport. Over nineteen percent $(19.9 \%)$ of those who were overweight or obese and $2.2 \%$ of those who were not overweight wanted to lose weight because of problems with clothes sizes. our participants in both groups believed that obesity heredity was little important. Furthermore the participants in both groups believed that obesity reduced 
by diet, with a non significant difference.

Another research study conducted by Davy et al. ${ }^{(15)}$ found that $94.4 \%$ of the students believed that it was important to eat different kind of foods and lose weight for being healthy. A total of 4 $(2.5 \%)$ and $25(11.9 \%)$ of the medical and non- medical students agreed that a balanced diet should be rich in proteins while none of the medical students and $11(5.2 \%)$ of the nonmedical students believed that a diet with high amount of carbohydrate was important to maintain a balanced diet (15).

Regarding beliefs about treatment of obesity, we found that $45.8 \%$ of the normal students and $53.7 \%$ of the overweight or obese participants believed that obesity may best be treated by the individual's effort to change the diet and exercise regime. In terms of the best way to treat obesity, $45 \%$ of normal and $38.5 \%$ of overweight or obese students believed that the dietitian is the best treatment method for combating obesity. The least common treatment option was surgery $(0 \%$ of overweight or obese and $0.3 \%$ of normal participants).

When we made regression analysis to identify risk factors of obesity in this study, we found that marital state, lack of physical activity, and watchingTV are considered as independent factors that predict obesity. Our findings were similar to what was reported by Menezes et al. ${ }^{(16)}$ as the results of their assessment showed that the time spent watching $\mathrm{TV}$, videogames and computers (indirect indicators of sedentarism) and lack of physical activity significantly associated with weight in univariate analysis, losing significance in the multivariate analysis. A study performed in Spain comprising adolescents with and without weight gain showed that the level of activity among eutrophic boys was significantly greater ${ }^{(17)}$, but a case control linked to a cohort study carried out in a Southern city of Brazil by Monteiro et al. (18) showed no association between physical activity and overweight or obesity. Similar results were described in other Brazilian case control studies by Neutzling et al. ${ }^{(19)}$ and Silveira et al. (20)

However, studies frequently found that college students, regardless of gender, have unhealthy eating habits may be due to the time constraints placed on them in order to accommodate their study habits ${ }^{(21,22)}$. Additional studies suggested that lack of motivation; lack of energy; lack of knowledge; physical injuries and cost were found to act as barriers against physical activity ${ }^{(23)}$.

A case-control study on risk factors for obesity and overweight in adolescents of private schools carried out in the city of Pelotas, Brazil, showed that obese father (OR 2.43), obese mother (OR 2.86), and overweight in childhood (OR 2.26) significantly increased the risk for overweight and obesity ${ }^{(19)}$. Additionally in Canada, Janssen et al. ${ }^{(24)}$ have shown that no fruit consumption was associated with elevated BMI values among adolescents. In a study on adolescents' profile in the USA, Neumaker-Sztainer et al. (25) showed that overweight adolescents or those not satisfied with their own weights, surprisingly consumed less fruits and greens. A study conducted on university students in Spain identified that low consumption of fruits and vegetables when compared to the Diet Quality Index ${ }^{(26)}$. 


\section{Conclusion}

We report that overweight and obesity were prevalent among the our study subjects as the prevelance was $38.5 \%$, lack of physical, soft drink consumpton and marital status were significantly associated with obesity, our students preferred dairy products and fatty foods over vegetables and fruits. In addition, their "lack of time" was the most frequently mentioned

\section{References}

1. Kanazawa M, Yoshiike N, Osaka T, Numba $\mathrm{Y}$, Zimmet $\mathrm{P}$, Inoue $\mathrm{S}$. Criteria and classification of obesity in Japan and Asia-Oceania. World review of nutrition and dietetics. 2005;94:1-12.

2. Haslam DW, James WP. Obesity. Lancet. 2005;366(9492):1197-209.

3. Musaiger AO, Hassan AS, Obeid O. The paradox of nutrition-related diseases in the Arab countries: the need for action. International journal of environmental research and public health. 2011;8(9):3637-71.

4. Sengupta A, Angeli F, Syamala TS, Dagnelie PC, van Schayck CP. Overweight and obesity prevalence among Indian women by place of residence and socio-economic status: Contrasting patterns from 'underweight states' and 'overweight states' of India. Social science \& medicine. 2015;138:161-9.

5. Tjepkema M .Adult obesity. Health reports. 2006;17(3):9-25.

6Berghofer A, Pischon T, Reinhold T, Apovian CM, Sharma AM, Willich SN. Obesity prevalence from a European perspective: a systematic review. BMC public health. 2008;8:200.

7.Adesina AF, Peterside O, Anochie I, Akani NA. Weight status of adolescents in secondary schools in port Harcourt using Body Mass Index (BMI). Italian journal of pediatrics. 2012;38:31.

8. Yahia N, Achkar A, Abdallah A, Rizk S. Eating habits and obesity among barrier to eating a healthy diet and engaging in regular exercise. Life style modification is important to improve healthy habits earlier in life. Emphasis should be given to implementing interventions aimed at increasing physical activity and encouraging healthier diets among students thereby reducing their future risk of chronic diseases.

Lebanese university students. Nutrition journal. 2008;7:32.

9. Horikawa C, Kodama S, Yachi Y, Heianza Y, Hirasawa R, Ibe Y, et al. Skipping breakfast and prevalence of overweight and obesity in Asian and Pacific regions: a meta-analysis. Preventive medicine. 2011;53(45):260-7.

10.Ganasegeran K, Al-Dubai SA, Qureshi AM, Al-abed AA, Am R, Aljunid SM. Social and psychological factors affecting eating habits among university students in a Malaysian medical school: a cross-sectional study. Nutrition journal. 2012;11:48.

11.Moy FM ،Johari S, Ismail Y, Mahad $\mathrm{R}$, Tie FH, Wan Ismail WA. Breakfast Skipping and Its Associated Factors among Undergraduates in a Public University in Kuala Lumpur. Malaysian journal of nutrition. 2009;15(2):165-74.

12. Malik VS, Schulze MB, Hu FB. Intake of sugar-sweetened beverages and weight gain: a systematic review. The American journal of clinical nutrition. 2006;84(2):274-88.

13.Pinto BM, Cherico NP, Szymanski L, Marcus BH. Longitudinal changes in college students' exercise participation. Journal of American college health : $\mathrm{J}$ of ACH. 1998;47(1):23-7.

14.ruz SY, Fabian C, Pagan I, Rios JL, Gonzalez AM, Betancourt J, et al. Physical activity and its 
associations

with

sociodemographic characteristics, dietary patterns, and perceived academic stress in students attending college in Puerto Rico. Puerto Rico health sciences journal. 2013;32(1):44-50.

15.Davy SR, Benes BA, Driskell JA. Sex differences in dieting trends, eating habits, and nutrition beliefs of a group of midwestern college students. Journal of the American Dietetic Association. 2006;106(10):1673-7.

16.Neutzling MB, Hallal PR, Araujo CL, Horta BL, Vieira Mde F, Menezes AM, et al. Infant feeding and obesity at 11 years: prospective birth cohort study. International journal of pediatric obesity : IJPO : an official journal of the International Association for the Study of Obesity. 2009;4(3):143-9. 17. Garaulet M, Martinez A, Victoria F, Perez-Llamas F, Ortega RM, Zamora S. Difference in dietary intake and activity level between normal-weight and overweight or obese adolescents. Journal of pediatric gastroenterology and nutrition. 2000;30(3):253-8.

18. Monteiro $\mathrm{P}$, Victora $\mathrm{C}$, Barros F.[Social, familial, and behavioral risk factors for obesity in adolescents]. Revista panamericana de salud publica $=$ Pan American journal of public health. 2004;16(4):250-8.

19.Neutzling MB, Taddei JA, Gigante DP. Risk factors of obesity among Brazilian adolescents: a case-control study. Public health nutrition. 2003;6(8):743-9.

20.Silveira D, Taddei JA, Escrivao MA, Oliveira FL, Ancona-Lopez F. Risk factors for overweight among
Brazilian adolescents of low-income families: a case-control study. Public health nutrition. 2006;9(4):421-8.

21.Chen G, Liu C, Yao J, Jiang Q, Chen N, Huang $\mathrm{H}$, et al. Overweight, obesity, and their associations with insulin resistance and beta-cell function among Chinese: a cross-sectional study in China. Metabolism: clinical and experimental. 2010;59(12):1823-32.

22.Al-Rethaiaa AS, Fahmy AE, AlShwaiyat NM. Obesity and eating habits among college students in Saudi Arabia: a cross sectional study. Nutrition journal. 2010;9:39.

23. Siddiqi Z, Tiro JA, Shuval K. Understanding impediments and enablers to physical activity among African American adults: a systematic review of qualitative studies. Health education research. 2011;26(6):1010-24.

24.Janssen I, Katzmarzyk PT, Boyce WF, King MA, Pickett W. Overweight and obesity in Canadian adolescents and their associations with dietary habits and physical activity patterns. The Journal of adolescent health : official publication of the Society for Adolescent Medicine. 2004;35(5):360-7.

25.Neumark-Sztainer D, Story $M$, Resnick MD, Blum RW. Correlates of inadequate fruit and vegetable consumption among adolescents. Preventive medicine.

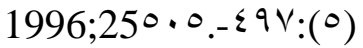

26. Arroyo Izaga M, Rocandio Pablo AM, Ansotegui Alday L, Pascual Apalauza E, Salces Beti I, Rebato Ochoa E. [Diet quality, overweight and obesity in university students]. Nutricion hospitalaria. 2006;21(6):673-9. 


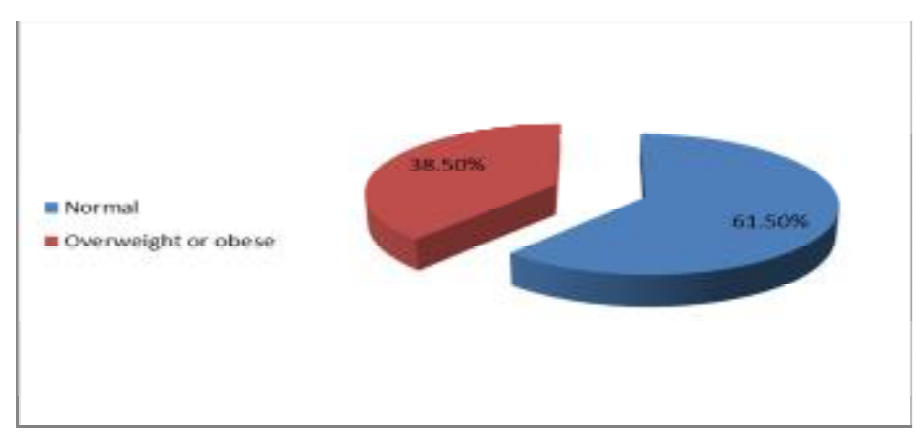

Figure 1. BMI distribution in Sohag University

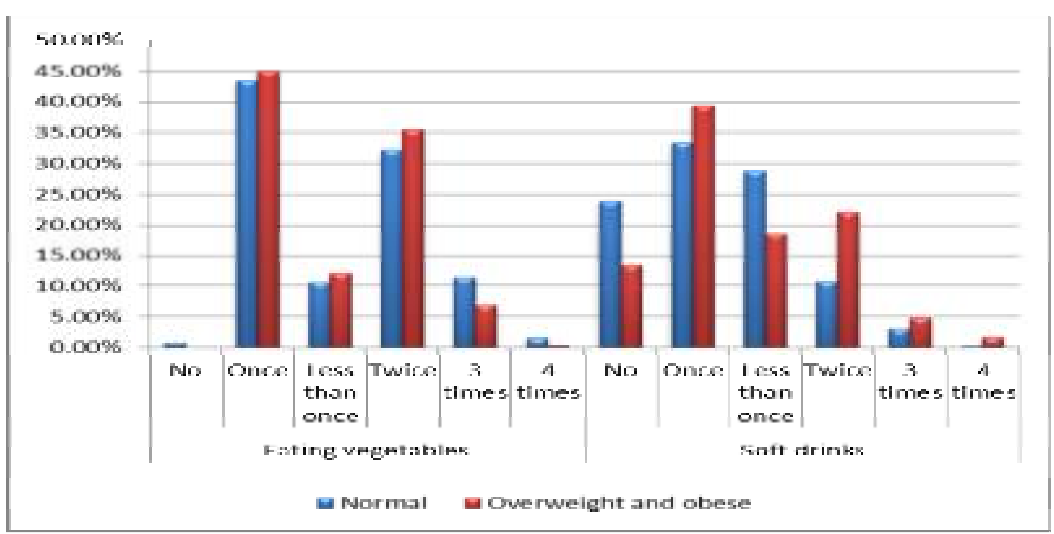

Figure (2): Vegetables and Soft drinks consumption.

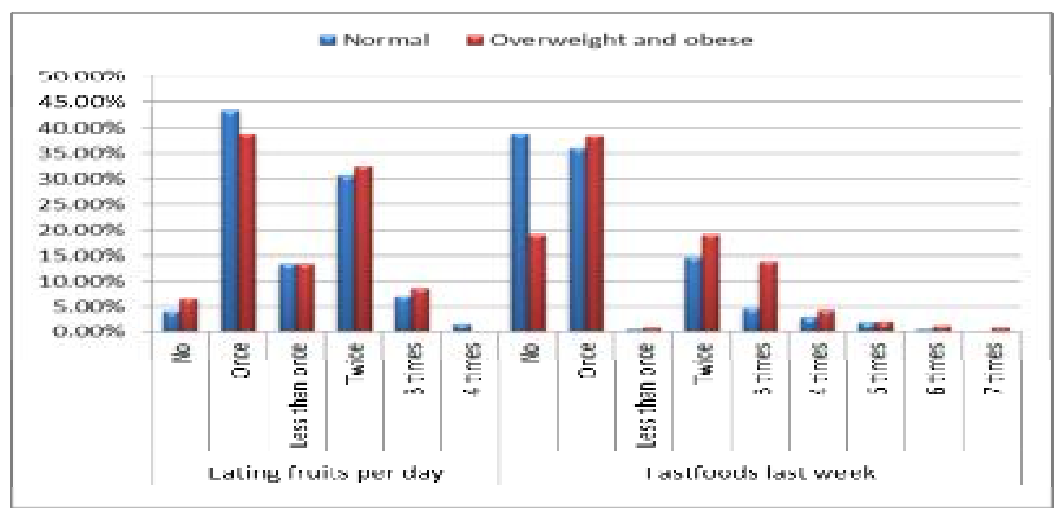

Figure (3): fruits and Fast foods consumption

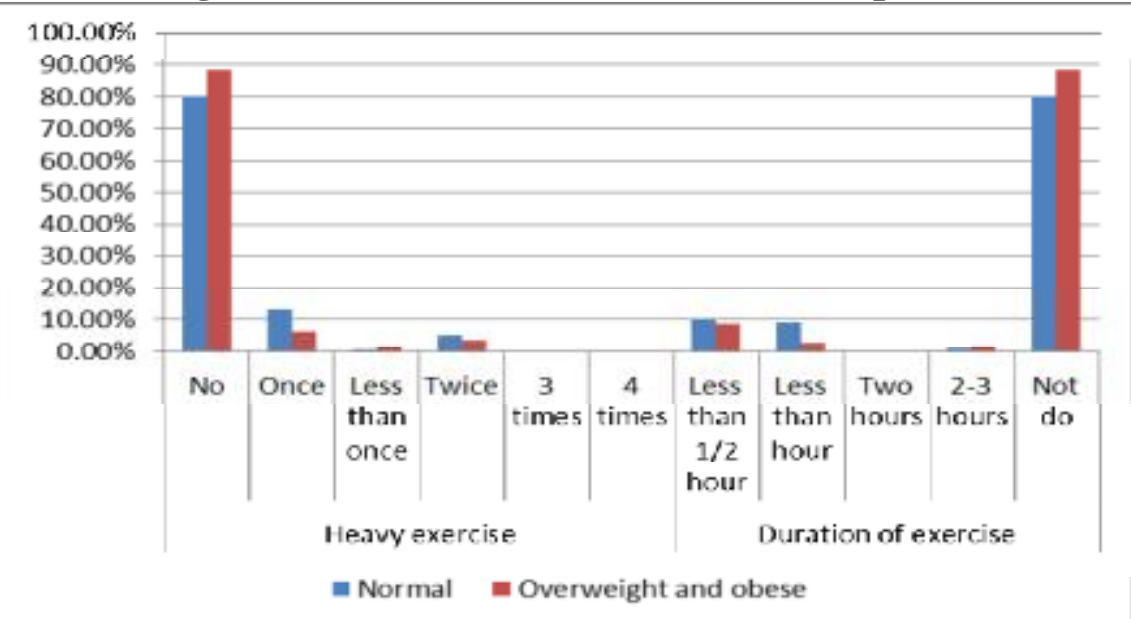

Figure (4): Details of participants' heavy exercise 
SOHAG MEDICAL JOURNAL A Study of Prevalence of Obesity among Female Students

Table 1. Weight, height, waist circumference and BMI of participants

\begin{tabular}{|c|c|c|c|}
\hline Variable (Group) & $\begin{array}{l}\text { Normal group } \\
(\text { Mean } \pm \text { SD) } \\
\text { N (369) }\end{array}$ & $\begin{array}{l}\text { Overweight or } \\
\text { obese group } \\
(\text { Mean } \pm \text { SD) } \\
\text { N }(231)\end{array}$ & P value \\
\hline Weight & $\mathbf{5 6 . 6 7} \pm 5.46$ & $70.90 \pm 6.65$ & $<0.001$ \\
\hline Length & $\mathbf{1 5 8 . 6 3} \pm 3.88$ & $159.16 \pm 3.19$ & 0.08 \\
\hline Waist circumference & $\mathbf{7 2 . 3 9} \pm 5.22$ & $\mathbf{8 0 . 9 6} \pm 5.56$ & $<0.001$ \\
\hline BMI & $22.51 \pm 1.83$ & $\mathbf{2 7 . 9 4} \pm 2.18$ & $<0.001$ \\
\hline
\end{tabular}

Table 2. Dietary behaviors and food consumption patterns

\begin{tabular}{|c|c|c|c|c|c|}
\hline \multicolumn{2}{|l|}{ Variable } & $\begin{array}{l}\text { Normal group } \\
\text { No }(\%)(369)\end{array}$ & $\begin{array}{l}\text { Overweight } \\
\text { obese group } \\
\text { No }(\%)(231)\end{array}$ & Chi square & $P$ value \\
\hline \multirow{5}{*}{$\begin{array}{c}\text { Breakfast } \\
\text { During last } \\
\text { month }\end{array}$} & 1_9/month & $94(25.5 \%)$ & $85(36.8 \%)$ & \multirow{5}{*}{13.920} & \multirow{5}{*}{0.008} \\
\hline & 10_19/month & $138(37.4 \%)$ & $83(35.9 \%)$ & & \\
\hline & 20_29/month & $43(11.7 \%)$ & $12(5.2 \%)$ & & \\
\hline & Always & $77(20.9 \%)$ & $39(16.9 \%)$ & & \\
\hline & No & $17(4.6 \%)$ & $12(5.2 \%)$ & & \\
\hline \multirow{6}{*}{$\begin{array}{c}\text { Cause of no } \\
\text { breakfast }\end{array}$} & $\begin{array}{l}\text { Can't eat in } \\
\text { morning }\end{array}$ & $87(23.6 \%)$ & $43(18.6 \%)$ & \multirow{6}{*}{62.915} & \multirow{6}{*}{$<0.001$} \\
\hline & No time & $124(33.5 \%)$ & $68(29.4 \%)$ & & \\
\hline & $\begin{array}{l}\text { Not find } \\
\text { prepared food }\end{array}$ & $64(17.4 \%)$ & $41(17.7 \%)$ & & \\
\hline & Other & $3(0.8 \%)$ & $1(0.4 \%)$ & & \\
\hline & Eat always & $90(24.4 \%)$ & $41(17.8 \%)$ & & \\
\hline & To lose weight & $1(0.3 \%)$ & $37(16.1 \%)$ & & \\
\hline \multirow{6}{*}{$\begin{array}{c}\text { Eating } \\
\text { fruits per } \\
\text { day } \\
\text { During last } \\
\text { month }\end{array}$} & No & $15(4.1 \%)$ & $15(6.5 \%)$ & \multirow{6}{*}{6.729} & \multirow{6}{*}{0.119} \\
\hline & Once daily & $160(43.4 \%)$ & $90(38.9 \%)$ & & \\
\hline & $\begin{array}{l}\text { Less than once } \\
\text { daily }\end{array}$ & $49(13.3 \%)$ & $31(13.4 \%)$ & & \\
\hline & Twice daily & $113(30.6 \%)$ & $75(32.5 \%)$ & & \\
\hline & 3 times daily & $26(7 \%)$ & $20(8.7 \%)$ & & \\
\hline & 4 times daily & $6(1.6 \%)$ & $0(0 \%)$ & & \\
\hline
\end{tabular}


SOHAg Medical JOURnal A Study of Prevalence of Obesity among Female Students

Farida S. Abdou

Table 3. Dairy products and fatty food

\begin{tabular}{|c|c|c|c|c|c|}
\hline Variable & (Group) & $\begin{array}{l}\text { Normal group } \\
\text { No }(\%)(\mathbf{3 6 9})\end{array}$ & $\begin{array}{l}\text { Overweight } \text { or } \\
\text { obese group } \\
\text { No }(\%)(231)\end{array}$ & Chi square & $P$ value \\
\hline \multirow{6}{*}{$\begin{array}{l}\text { Dairy } \\
\text { products } \\
\text { During last } \\
\text { month }\end{array}$} & No & $47(12.7 \%)$ & $19(8.2 \%)$ & \multirow{6}{*}{13.992} & \multirow{6}{*}{0.01} \\
\hline & Once daily & $180(48.8 \%)$ & $110(47.6 \%)$ & & \\
\hline & $\begin{array}{l}\text { Less than once } \\
\text { daily }\end{array}$ & $56(15.2 \%)$ & $21(9.1 \%)$ & & \\
\hline & Twice daily & $69(18.7 \%)$ & $63(27.3 \%)$ & & \\
\hline & 3 times daily & $14(3.8 \%)$ & $15(6.5 \%)$ & & \\
\hline & 4 times daily & $3(0.8 \%)$ & $3(1.3 \%)$ & & \\
\hline \multirow{8}{*}{$\begin{array}{l}\text { Fatty food } \\
\text { During last } \\
\text { month }\end{array}$} & No & $3(0.8 \%)$ & $2(0.9 \%)$ & \multirow{8}{*}{21.312} & \multirow{8}{*}{0.002} \\
\hline & Once daily & $140(37.9 \%)$ & $72(31.1 \%)$ & & \\
\hline & $\begin{array}{l}\text { Less than once } \\
\text { daily }\end{array}$ & $45(12.2 \%)$ & $10(4.3 \%)$ & & \\
\hline & Twice daily & $124(33.6 \%)$ & $88(38.1 \%)$ & & \\
\hline & 3 times daily & $35(9.5 \%)$ & $39(16.9 \%)$ & & \\
\hline & 4 times daily & $19(5.1 \%)$ & $17(7.4 \%)$ & & \\
\hline & 5 times daily & $1(0.4 \%)$ & $0(0 \%)$ & & \\
\hline & More than 5 daily & $2(0.5 \%)$ & $3(1.3 \%)$ & & \\
\hline
\end{tabular}

Table 4. Univariate Binary Regression Analysis between normal participants and overweight or obese participants

\begin{tabular}{|c|c|c|c|c|c|}
\hline & $\mathrm{B}$ & $\mathrm{P}$ value & \multirow{2}{*}{$\begin{array}{c}\text { Odd's } \\
\text { ratio }\end{array}$} & & \multicolumn{2}{|c|}{ CI for Odd's } \\
\cline { 4 - 6 } & & & & Lowe & Upper \\
& & & $\mathrm{r}$ & \\
\hline Age & 0.000 & 0.994 & 1.000 & 0.895 & 1.119 \\
\hline Marital status & 1.257 & $<\mathbf{0 . 0 0 1}$ & 3.515 & 1.809 & 6.830 \\
\hline Breakfast & 0.474 & 0.738 & 1.607 & 0.100 & 25.818 \\
\hline Eating fruits & 0.497 & 0.200 & 1.644 & 0.769 & 3.514 \\
\hline $\begin{array}{c}\text { Eating } \\
\text { vegetables }\end{array}$ & -20.7 & 1.000 & 0.000 & 0.000 & $\cdot$ \\
\hline Soft drinks & -0.646 & $\mathbf{0 . 0 5 2}$ & 0.524 & 0.273 & 1.007 \\
\hline Exercise & 0.582 & $\mathbf{0 . 0 1 4}$ & 1.789 & 1.125 & 2.845 \\
\hline Watching TV & -0.610 & $\mathbf{0 . 0 5 1}$ & 0.543 & 0.294 & 1.004 \\
\hline $\begin{array}{c}\text { Walking 10 } \\
\text { minutes }\end{array}$ & -20.73 & 0.999 & 0.000 & 0.000 &. \\
\hline
\end{tabular}


SOHAg MEdical JOURnal A Study of Prevalence of Obesity among Female Students

Table 5. Multivariate Binary Regression Analysis between normal participants and overweight or obese participants Regarding marital state, soft drinks, exercise, and watching TV

\begin{tabular}{|c|c|c|c|c|c|}
\hline & $\mathrm{B}$ & $\mathrm{P}$ value & Odd' & \multicolumn{2}{|c|}{ CI for Odd's } \\
\cline { 4 - 6 } & & & $\begin{array}{c}\mathrm{s} \\
\text { ratio }\end{array}$ & Lower & Upper \\
\hline Marital status & -1.222 & $\mathbf{< . 0 0 1}$ & $\begin{array}{c}0.29 \\
5\end{array}$ & 0.150 & 0.578 \\
\hline Soft drinks & -0.617 & 0.079 & $\begin{array}{c}0.54 \\
0\end{array}$ & 0.278 & 1.050 \\
\hline Exercise & 0.572 & $\mathbf{0 . 0 1 7}$ & $\begin{array}{c}1.77 \\
2\end{array}$ & 1.106 & 2.840 \\
\hline Watching TV & -0.649 & $\mathbf{0 . 0 4 3}$ & 0.52 & 0.279 & 0.980 \\
\hline
\end{tabular}

Table 6. Final model of multivariate logistic regression.

\begin{tabular}{|c|c|c|c|c|c|}
\hline & \multirow[t]{2}{*}{ B } & \multirow[t]{2}{*}{$P$ value } & \multirow{2}{*}{$\begin{array}{c}\text { Odd' } \\
\mathrm{s} \\
\text { ratio }\end{array}$} & \multicolumn{2}{|c|}{ CI for Odd's } \\
\hline & & & & Lower & Upper \\
\hline Marital status & 1.219 & $<0.001$ & $\begin{array}{c}3.38 \\
3 \\
\end{array}$ & 1.730 & 6.614 \\
\hline Exercise & 0.571 & 0.017 & $\begin{array}{c}1.77 \\
1 \\
\end{array}$ & 1.106 & 2.834 \\
\hline Watching TV & -0.688 & 0.031 & 0.50 & 0.269 & 0.941 \\
\hline
\end{tabular}

